\title{
Applying "willingness to pay" approach for evaluation of economic impact from the world's biggest sporting events
}

\author{
Elena Gureeva ${ }^{1, a}$, Ilya Solntsev,b, Nikita Osokin ${ }^{3, \mathrm{c}}$ and Tatiana Skryl ${ }^{4, \mathrm{~d}^{*}}$ \\ ${ }^{1234}$ Stremyannyi lane, 36, Moscow, Russia \\ amakarova_ea@mail.ru, bSolntsev.iv@rea.ru, cbeaver523@yahoo.com, dt_skryl@mail.ru
}

${ }^{*}$ Corresponding author

\begin{abstract}
Keywords: Economic impact, Sports economics, Economics of major sporting events, Football economics, 2018 FIFA World Cup

Abstract. This article analyses the approaches for evaluating the economic impact from the world's top sporting events, with the focus on the "willingness to pay" technique. The variations of this model and basic assumptions are also assessed. Authors developed their own social research study dedicated to measuring the willingness of Russian citizens to fund top sporting events, particularly focusing on the examples of the 2018 FIFA World Cup.
\end{abstract}

\section{Introduction}

Such mega events, as Olympic Games and FIFA World Cup, require substantial funds for the construction of sports facilities, appropriate transport systems, service infrastructure, etc. Although these sporting events last only several weeks, sometimes their long-term economic impact on the country/region can last for several years. The first socioeconomic results of the project "Russia-2018" have been already determined, but the data has a fluctuating tendency in various reports. The main problem is the lack of a common method for comprehensive evaluation of the effectiveness of such events. Major sporting events provide not only an outstanding sporting spectacle, but also contribute a definite economic benefit to the host country or region. Four areas are usually influenced (excluding intangible benefits): sports infrastructure, transport infrastructure, tourism and employment.

Despite the obvious benefits from hosting major sporting events for each of the above-mentioned areas, it is difficult to measure the specific effect caused by the event in monetary terms.

Literature Review on economic benefits from top sporting events: The problems estimating the impact of mega events are being mentioned in the works of many authors, but estimates of the cumulative effect of the same sporting event may vary depending on the method being used. For example, the results of exante calculations (when conducted before the event) are usually much higher than the results of ex-post analysis (when the study is conducted after the completion of the event)[1]. This can be caused by the fact that in the latter case all data involved including those about tourists and their spending in the region during the mega-event are more accurate. Whereas before the event, analysts are forced to rely on the experience gained from previous events hosted in other countries, therefore a large number of assumptions should be made. At the same time, costs for construction and renovation of stadiums, transport and engineering infrastructure are often underestimated. Many ex-ante studies predict major employment benefits that are extremely difficult to find afterwards[2]. If there are any employment benefits at all, they are likely to be small and temporary, and for unskilled labor in particular[3]. Matheson[4][5][6] concludes that several effects are often overestimated or even completely forgotten in ex ante studies:

- The substitution effect: expenditures related to the tournament are considered extra expenditures, while these costs are diverted from other economy sectors.

- Time-switching: people who attend an event would have come anyway, but at another time.

- Crowding-out effects with regard to tourists: a portion of regular tourists will avoid cities which are highly crowded during the event.

- Leakage effect: many expenditures do not remain in the local economy but are transferred to the international sports federation or similar entities. 
- Benefits and expenditures occurred after the event are ignored.

- Not all effects are considered (e.g., traffic congestion, construction-related inconvenience, vandalism, environmental pollution, disruptions of the residents' life).

Richard Cashman[7] identifies six segments of heritage: the economy; infrastructure; information and education; social life, politics and culture; sports; symbolism, and history. There are a significant number of studies concerning the economic impact of certain major sporting events.

\section{Methodology}

Two main methods are used for this purpose: willingness-to-pay (WTP) and willingness-to-accept (WTA) approaches. Virtually these methods are implicated with the help of surveys which are intended to evaluate the consumers' "willingnessto pay" for a particular product or to avoid the loss of this good or service. The "willingness-to-pay" method is able to assess the actual amount that can be derived from person's income[8]. While at the same this person would not lower their socioeconomic usefulness, which mostly depends on personal characteristics affecting the balance between a consumer's income and the use of a quality product (in our case - a well-organized top sporting event). The assessment of the consumers' WTP is known to be one of the ways of evaluating consumer benefits from social and economic improvements. This is done by comparison the amount people are willing to pay and the cost of a particular product[9]. The advantages of the willingnessto-pay method include:

- relative simplicity of the survey;

- method can be used in ex-post analysis (after implementation) as well as in ex-ante analysis (before implementation) for any given project;

- accuracy of survey' results is provided by the conservative calculating approaches;

- wide access to statistical data.

Any person without specific professional background or education can answer a simple hypothetical question[10][11]. In most cases, the process of gathering WTP-data is conducted with the help of questionnaires that are constructed for evaluating the consumer's willingness to have access to a particular product. This tool may easily be interpreted as compensating variation - a theoretically based measurement instrument for assessing welfare, which can be also used in a cost/benefit analysis.

Here is a description of the methods related to constructing a reliable WTP questionnaire: Openended WTP. In this method, respondents are asked to name the maximum WTP for a particular good or service without being given an array of alternatives to choose from. This particular method may not always be applicable due to the possibility of unrealistic responses. Close-ended iterative bidding. Respondents are asked if they are willing to pay a certain amount form a particular product. If the response is positive then the respondent will be asked the same question with a larger amount in the equation repeatedly until the response is negative. If the initial response was negative, the amount will be lowered until the point of a positive response. This method is widely implemented. However, there is evidence that suggests that there is a response bias that depends on the initially set price for the product.

Contingent ranking. Respondents are asked to rank specific combinations of quantities of the product and their willingness to pay for this product. For example, these combinations can vary from low product quality at a low price and high product quality at a higher price. The combinations may be ranked from most preferred and least preferred and vice versa. This method is popular due to the simplicity of its format. Dichotomous choice. In this method, respondents are presented with an array of randomly assigned prices. During the analysis of the responses, a table of response distributions is constructed and the probability of a positive answer from the respondent is calculated. The method requires the attraction of large database of respondents for the results to be statistically significant and, therefore, be able to determine if the population is willing to pay for this particular kind of goods or service. During the process of constructing WTP surveys a simultaneous combination of different methods is acceptable. The survey itself may be conducted anonymously in the traditional form of 
paper-sheet questionnaires as well with the use of various Internet platforms, e-mail and social networks, thereby eliminating survey bias that arises from personal questioning.

\section{Results and Discussion}

In order to obtain WTP-data about top sporting events among Russian citizens a survey was conducted with more than 350 respondents involved. The survey was carried out with the help paper sheet questionnaires and Internet voting.

\subsection{Survey overview}

During the course of the survey, the significance level of the aftermath aspects of top sporting events was determined. Respondents were asked to rank tangible and intangible aspects of the top sporting aftermath. Each aspect was supposed to be ranked on a scale from 1 to 7 (1 - absolutely insignificant, 7 - the most significant). Every one of the post-sporting event aspects was picked as the most important at least once. However, in the eyes of the respondents, the most significant were the tangible factors, such as sports and tourism infrastructure (140 and 41\%, respectively). The fact that these aspects received the least amount of "insignificance" responses should also be taken into account. The Intangible aspects of the top sporting event aftermath like the improvement of a country's image on the world stage as the possibility to see world-class athletes received practically identical results; another fact is that both these factors received the highest amounts of "insignificance" responses (11 and $15 \%$ respectively). At the same time, respondents gave very similar responses to the aspects of a country's improved tourist attractiveness and the expenditure of workplaces. The next part of the survey was intended to elicit actual amounts of money that people were willing to pay annually for the organization of a top sporting event. This question was constructed in the form of a payment card with a price range. Respondents were asked to choose from a range of sums the amount they were comfortable with paying annually. This particular question was designed specifically to determine consumers' WTP.

\subsection{Data analysis}

Therefore, $33 \%$ of the respondents are either unwilling to pay or are just ready contribute and unsubstantial sum (no more than 100 RUB $=1.5$ USD) to the organization of a Top sporting event. Though, at the same time, 13\% of the population is willing to spend 5000 RUB (75 USD) and more. The average amount that people are willing to pay which calculated based on all of the results was 1233 RUB (18 USD) since the majority of the respondents gave preference to the option of contributing a sum of 1000 RUB (15 USD). At the beginning of 2018, the number of employed people in Russia amounted to 72 million.

If the results of the WTP survey are transferred on the scale of the country than we would get the approximate amount that Russian citizens are willing to pay annually for the organization of top sporting events - this sum is slightly more than 88,8 billion RUB ( 1.3 billion USD). The preparation stage of organizing a top sporting event from the point of winning the bidding process to actually hosting the event is quite long ( 8 years for the FIFA World Cup). Consequently, during the whole preparation stage an amount of 710 billion RUB (10.6 billion USD) could be reached. The CEO of the organizing committee of «Russia-2018» Mr. Alexey Sorokin said that the costs of organizing the 2018 FIFA World Cup in Russia is estimated in the amount of 683 RUB (13,2 billion USD). Hence, the cost of hosting the 2018 FIFA World Cup equals and even slightly precedes the population's willingness to pay for organizing the event inside the country.

\section{Summary}

From the conducted survey based on the WTP method, we were able to determine that both tangible and intangible aspects of the aftermath from hosting a top sporting event are significantly important to the population. At the same time, a substantial number of people are ready to fund these sorts of projects. Though the majority is willing to spend the minimal amounts, even these additional 
resources can prove to be crucial for Russia. It also has to be stated that the majority of citizens disagrees with the introduction of a new tax for this purpose or the increase of the interest rate of other taxes as well. The fact that the obtained data largely depends on the opinions of the respondents also has to be taken into account. Therefore, it is accurate to acknowledge that the results could vary with the increase of the amount of questioned people. These will the subject of our future research.

\section{References}

[1] Scelles N., Andreff W. Economic model of a professional football club in France (Book Chapter). Routledge Handbook of Football Marketing, 2017

[2] Holger Preuss. Lasting Effects of Major Sporting Events. URL: http://idrottsforum.org/articles/preuss/preuss061213.html

[3] Holger Preuss, Norbert Schütte, Thomas Könecke, Lamartine DaCosta. Olympic Ideals as seen by Olympic Scholars and Experts. Mainzer Papers on Sports Economics \& Management № 13, March 2014

[4] Matheson, Victor A. Assessing the infrastructure impact of mega-events in emerging economics. URL: http//www.holycross.edu/departments/economics/website, September 2012

[5] Matheson, Victor A. Mega-Events: The effect of the world's biggest sporting events on local, regional, and national economies. URL: http//www.holycross.edu/departments/economics/website, October 2016

[6] Matheson, Victor A. Economic multipliers and mega-event analysis. International Journal of Sport Finance Publisher: Fitness Information. Pp. 99, Feb, 2009

[7] Cashman, R. Legacy and sustainability aims and outcomes at the Olympic Games and the Football World Cup (Book Chapter). Managing Sport Mega-Events, 2016

[8] Gureyeva E.A., Skryl T.V., Sukhanovsky Y.A., Askarov A.D. Economic benefits of mass sport events. Teoriya i Praktika Fizicheskoy Kultury, pp. 19, 2017

[9] Michiel de Nooij, Marcel van den Berg, Carl Koopmans. Bread or games? Social costbenefit analysis of the World Cup in the Netherlands. Amsterdam, augustus 2010. SEO Economic Research.

[10]Roger G. Noll, Andrew Zimbalist. Sports, Jobs \& Taxes. The Brooking institution press, Washington D.C., 1997

[11]Roger G. Noll, Attendance and price setting in Roger G. Noll, ed., Government and the sports business, pp. 115-58, 2014 